\title{
DARK TURISMO: A POSSIBILIDADE DE UM ELO ENTRE O TURISMO E OS RESULTADOS DA VIOLÊNCIA URBANA
}

\section{DARK TOURISM: THE POSSIBILITY OF A LINK BETWEEN TOURISM AND THE RESULTS OF URBAN VIOLENCE}

\author{
Luana Aparecida Trzaskos ${ }^{1}$ \\ Márcia Dropa ${ }^{2}$ \\ Luiz Fernando de Souza ${ }^{3}$
}

\begin{abstract}
RESUMO
Este trabalho tem por objetivo refletir sobre os elos estabelecidos entre a atividade turística e os impactos gerados pela violência urbana. Tornando-se um conceito a ser aplicado, surge o Dark Turismo, tendência que tem seus estudos em crescimento, apesar de alguns atrativos ligados a esta segmentação serem utilizados como destinos diretos ou indiretos. Para o embasamento desta pesquisa, foram utilizadas referências bibliográficas que vão além do campo de Turismo. O foco deste artigo são os cenários marcados pela violência que posteriormente tornaram-se cenários turísticos, precisamente os casos do Rio de Janeiro, no caso da Chacina da Candelária. Finalmente, representou-se nítida a importância de desenvolver esta temática em novas pesquisas, pois as referências atuais são escassas. Por tratar-se de um assunto novo, torna-se cada vez mais instigante em virtude de sua função referente ao repasse de informação e conhecimento, tendo em vista que se destaca como um objetivo do Dark Turismo, propiciar a sensibilização da sociedade contemporânea sobre atos frustrados, principalmente os que tiveram ação negativa ao próximo. Considera-se que o Dark Turismo pode atuar como agente de reflexão, possibilitando mudanças no que diz respeito à atual situação da sociedade perante as ações decorrentes da violência urbana.
\end{abstract}

Palavras-Chave: Dark Turismo. Violência. Cenários.

\begin{abstract}
This work reflects on the links established between tourism and the impacts of urban violence. Turning into a concept to be applied, the Dark Tourism is a trend that has its studies on growth, although some attractions linked to this segmentation are used as direct or indirect targets. For the basis of this research, references that go beyond the field of tourism were used. The article focuses on scenarios characterized by violence, which later became scenarios for tourism, especially in the case of the "Candelária Massacre", in Rio de Janeiro, Brazil. Finally, the importance of developing new researches on this subject was emphasized, for the current references are scarce. As a new subject, it becomes increasingly compelling because of its role regarding the transfer of information and knowledge in order

1 Graduada em Bacharelado em Turismo pela Universidade Estadual de Ponta Grossa. E-mail: luana.trz@hotmail.com

2 Mestre em História pela Universidade Estadual Paulista Júlio de Mesquita Filho (UNESP). Professora Assistente da Universidade Estadual de Ponta Grossa.

3 Doutor em Engenharia de Produção pela Universidade Federal de Santa Catarina (UFSC). Professor da Universidade Estadual de Ponta Grossa. E-mail:
\end{abstract} E-mail: mdropa@gmail.com luizfersouza@uol.com.br 
to stand it out as a target of Dark Tourism the awareness of contemporary society about frustrated actions, mainly the one which were negative to people. Dark tourism can act as an agent of reflection, enabling changes in the relation between society and urban violence.

Keywords: Dark Tourism. Violence. Scenarios.

\section{INTRODUÇÃO}

Este trabalho tem o objetivo de salientar os elos estabelecidos na atividade turística em cenários decorrentes dos impactos gerados pela violência urbana. Pode-se dizer que o turismo, se bem planejado, tem o potencial de propiciar a reflexão sobre atitudes de conflito nos espaços demarcados por visitas decorrentes da curiosidade sobre tragédias advindas do processo da violência.

Sendo assim, o turismo pode atuar como um "grito" da sociedade marginalizada que tem o intuito de mudar a atual realidade. Dessa forma, parte-se do princípio de que o turismo tem um foco social e que, segundo o pressuposto de McIntosh (MCINTOSH, 1977, p. 34 apud BENI 1998,), “pode ser definido como a ciência, a arte e a atividade de atrair e transportar visitantes, alojá-los e cortesmente satisfazer suas necessidades e desejos".

Considerando a subjetividade do indivíduo, e assim aplicando a sensibilização do olhar do turista, considera-se a personalidade do indivíduo, como afirma Ross (2001, p. 45):

(...) dizem que a personalidade também pode se referir a características duradouras. Schultz afirma que os teóricos pressupõem um certo grau de estabilidade e previsibilidade de um indivíduo. Portanto, personalidade não é algo rígido e imutável. (...) cada um de nós temos uma personalidade única e irrepetível.

Dessa forma, adentra-se um campo psicológico, onde se avalia os destinos visitados, conforme o interesse de cada indivíduo, que, segundo a regra no turismo, são locais que proporcionam realização e bem-estar. Contudo, alguns cenários, não tão bem vistos assim, estão recebendo visitação e até podem ser considerados peças integrantes do turismo cultural devido à importância histórica e informação repassada. São os cenários de Dark Turismo (ou turismo sombrio).
Na sociedade atual, o Dark Turismo (LENNON \& FOLEY, 2000) vem demarcando seu território e estabelecendo sua principal motivação que é explorar lugares que foram palcos de tragédias, catástrofes ou que transmitem um sentimento de sofrimento. Conforme Seaton (1996, p. 240 apud PREZZI, 2008, p. 16), caracteriza-se por Dark Turismo o deslocamento para um local total ou parcialmente motivado pelo desejo de encontro real ou simbólico com a morte, seja ela violenta ou não, e cuja motivação pode ser desencadeada em níveis diferentes pelas intenções pessoais daqueles cujo foco é a morte.

Desta maneira, busca-se também com a atividade turística uma forma de conscientizar as pessoas em relação à violência urbana, que pode ser vista e relembrada com a visitação de locais que foram palco de tragédias e mortes; assim, há o intuito, um apelo visual e psicológico, para que este atrativo torne-se também um meio de combater a própria violência.

A realização deste trabalho teve por objetivo principal reconhecer o Dark Turismo, caracterizando a utilização de espaços marcados pela violência como cenários turísticos.

A metodologia utilizada foi a da pesquisa exploratória, no que diz respeito ao objeto de estudo, e a da pesquisa bibliográfica com base em referenciais teóricos que embasaram a construção do conhecimento sobre os diversos eixos que compõem o Dark Turismo.

A importância deste trabalho pode ser justificada pela existência de visitação a esses locais, sendo necessário o planejamento turístico adequado. Afinal se há demanda, o profissional bacharel em turismo deve estar apto para atuar neste sentido, reconhecer sua função de aceitar as diversidades, planejar meios de interpretação da história e divulgação, e não esquecer que deve agir sempre com ética, pois são lugares que refletem a dor de várias famílias. 


\section{BREVE ANÁLISE SOBRE AS PERSPECTIVAS DA ATIVIDADE TURÍSTICA}

O turismo vem demarcando seu espaço como uma das atividades do setor de prestação de serviços que mais cresce, embora sua dinâmica teórica seja constante, pois estabelece uma gama de conceituações, que proporcionam ao indivíduo a liberdade para que avaliar as informações assimiladas.

As temáticas que compõem o turismo vêm se ampliando por meio da estruturação dos segmentos do mercado de turismo, que visam formatar o produto conforme o desejo do cliente e assim ampliar o campo de oferta e o reconhecimento de novas tendências, como é o caso do Dark Turismo.

Conforme estabelecido pela Organização Mundial do Turismo - OMT (2001) apud Ministério do Turismo (2008), o turismo compreende atividades em que as pessoas realizam viagens e estadas em lugares diferentes de sua residência, por menos de um ano e com finalidades diversas.

Em alguns casos, há autores que definem o turismo como uma atividade de permanência superior a 24 horas fora de sua residência fixa; no entanto, analisando esta definição e partindo da realidade atual, essas afirmações podem ser consideras falhas. A globalização vem aproximando as pessoas umas das outras, até mesmo em relação ao deslocamento, a aviação tem facilitado e diminuído a duração das viagens.

O turismo tem se mostrado a área de maior crescimento nos dias atuais, servindo de suporte da economia de muitas regiões; por isso, o mercado tem utilizado cada vez mais profissionais do turismo, fazendo que muitos vejam esse campo como técnico. Por outro lado, o turismo abrange o deslocamento de pessoas e suas relações.

Moesh também define a atividade turística, destacando as subjetividades que motivam cada indivíduo, ou seja, aquelas que intensificam e proporcionam seu deslocamento. Além disso, ressalta que o turismo torna-se uma alternativa para novas experiências em busca de realização, para cujo sujeito tenha despertado a partir de seu cotidiano.

O turismo é um campo de práticas histórico-sociais, que pressupõem o deslocamento do(s) sujeito(s), em tempos e espaços produzidos de forma obje- tiva, possibilitador de afastamentos simbólicos do cotidiano, coberto de subjetividades, portanto, explicitadores de uma nova estética diante da busca do prazer. (MOESH. p.134. 2002)

Conforme o despertar das necessidades de cada indivíduo, é possível notar a subjetividade presente, pois cada motivação será desencadeada de forma diferente, uma vez que o instinto de cada qual é díspar, e no caso da escolha do destino de viagem, as preferências também variam para cada um.

Não existe um único olhar do turista enquanto tal. Ele varia de acordo com a sociedade, o grupo social e o período histórico. Tais olhares são construídos por meio da diferença. Com isso quero dizer que não existe apenas uma experiência universal verdadeira para todos os turistas, em todas as épocas. Na verdade, o olhar do turista, em qualquer período histórico, é construído em relacionamento com seu oposto, com formas não turísticas de experiência e de consciência social: o que faz que um determinado olhar do turista dependa daquilo com que ele contrasta. (URRY, p.16, 1996)

A subjetividade está diretamente entrelaçada ao "olhar do turista", dependendo das vivências ao qual ele está submetido, sugerindo assim os temas que detêm sua atenção. Neste caso, enquadra-se o Dark Turismo, que se opõe a características comuns buscadas pela demanda turística.

Notam-se aí, segundo Menezes (2008), padrões de consumos mais individualizados e segmentados do que aqueles presentes no chamado "turismo "contemporâneo". Utiliza-se, então, da segmentação para agrupar pessoas com desejos e necessidades semelhantes, o que possibilita a identificação do Dark Turismo, bem como uma segmentação que deve ser planejada e estruturada, ressaltando que cabe ao profissional de turismo manter-se atento e apto a estruturar a atividade turística.

A motivação para uma viagem pode ser comparada aos estímulos gerados ao praticar uma atividade de aventura ou ao assistir a um filme de terror.

Por exemplo: a grande história de aventura ou o grande filme de aventuras nos segura e nos mantém nas poltronas à medida que nos identificamos com pessoas fictícias ameaçadas por criaturas poderosas, aparentemente invencíveis, espíritos, 
holocaustos, terremotos, tubarões. O envolvimento que estas aventuras suscitam reflete nosso instinto básico de sobrevivência. O sentimento de assumir um risco básico de sobreviver é revigorador: dá um novo sentido à vida. Seguramente esta é a razão pela qual os esportes que implicam risco são tão excitantes. (VISCOTT, 1982, p. 48-49).

Conforme o autor sugere, o sentimento de assumir um risco ao comparar-se com o personagem, instigado pelo risco de "conseguir sobreviver", pode ser a razão motivadora de determinada atividade. Com a atividade turística não é diferente, a visita aos cenários sombrios pode ser vista como um estímulo a este espírito de sobrevivência perante diversas situações.

Por conseguinte, o exemplo anterior pode ser voltado ao destino escolhido e às atrações que serão visitadas, onde o indivíduo estará dispondo-se a enfrentar situações de ameaças, por recordar das histórias que envolvem o local, o que evidencia o Dark Turismo.

Contudo, deve-se ressaltar a importância do marketing turístico que será aplicado, para que não seja levado pelo sensacionalismo, com foco ligado a situações sombrias, que envolvem perdas de familiares, dor e sofrimento. Atingir as expectativas do cliente, com diferencial e singularidade, exige um processo que busque envolvê-lo em um plano estratégico que compreende necessidades da demanda potencial. Entretanto, é preciso atuar de forma ética, e não usar a tristeza do próximo para acarretar sucesso.

\section{DARK TURISMO: UM CENÁRIO CONCEITUAL}

O Dark Turismo, diferenciando-se de outras atrações turísticas, desconsidera apenas os locais que propiciam bem-estar e lazer, os quais muitas vezes definem o turismo, pois as visitas acontecem em cenários marcados por reações de sofrimento e morte. Composto por atrações vinculadas a fatores que até certo período da história eram deixados de lado, por se tratarem de 'mal-estar para a humanidade', devido aos resultados gerados, ignorar esses locais era uma forma de esquecer o mal causado, seja por ações humanas, ou pelo extermínio de pessoas, catástrofes que ceifaram vidas, até mesmo diversas outras situações não relacionadas diretamente com a morte, mas com o sofrimento.
Os princípios de Dark Turismo têm sua base há séculos, como as batalhas de gladiadores, em Roma, execuções que eram efetuadas durante o período da Inquisição e as peregrinações às catacumbas dos 'santos' católicos, entre tantos outros exemplos, considerando que tais eventos atraíam grande número de expectadores e visitantes.

O Dark Turismo é uma experiência turística diferenciada, pois as visitas têm como destino locais incomuns, que muitas vezes despertam repugnância, por serem "locais de morte", o que o caracteriza fora das formas mais tradicionais, e torna díspar as segmentações já conhecidas do mercado turístico, difundidas e consolidadas.

O próprio nome Dark Turismo é um fator propício a despertar curiosidade sobre o assunto, pois se trata de um termo que direciona ao sombrio. Segundo o Oxford Dictionary, ${ }^{4}$ dark tem sua tradução como "escuro", "sombrio", definindo, portanto, o "Turismo Sombrio", um tema que provoca conflitos em si, advindo de assuntos que geram questionamentos no ser humano e que possibilitam reflexões. Justifica-se, portanto, um estudo a respeito do tema.

Dark Turismo é o deslocamento para um local total ou parcialmente motivado pelo desejo de encontro real ou simbólico com a morte, seja ela violenta ou não e cuja motivação pode ser desencadeada em níveis diferentes pelas intenções pessoais daqueles cuja morte é seu foco. (SEATON 1996. p.240 apud Ribeiro 2010).

A partir de 2005, houve a criação de um grupo de pesquisadores de várias partes do mundo, organizado pela University of Central Lancashire ${ }^{5}$, na Inglaterra, o The Dark Tourism Forum ${ }^{6}$, que tem o intuito de incentivar a pesquisa sobre o Dark Turismo, justificando sua procura e a forma com que deve ser abordado.

O estudo do Dark Turismo é justificável e importante por uma série de razões. Geralmente, lugares de turismo sombrio, atrações e exposições não são apenas numerosos, mas também têm enorme variação. Consequentemente, todos esses lugares, atrações e exposições exigem desenvolvimento eficaz e adequado, gestão, interpretação e promoção. Estes, por sua vez, exigem uma compreensão

\footnotetext{
4 Dicionário de Oxford.

5 Universidade Central de Lancashire.

6 Fórum de Dark Turismo.
} 
mais completa do fenômeno do turismo sombrio dentro de contextos sociais mais amplos, cultural, histórico e político. (Disponível em: <http://www. dark-tourism.org.uk>. Acesso em: 15 set. 2012).

O número de visitantes em territórios caracterizados por questões históricas ou fictícias ligadas ao símbolo de morte, tendem a crescer ainda mais, uma vez que os números já vêm sendo observados há alguns anos, chamando a atenção e promovendo o reconhecimento do índice que gradativamente aumenta, originando a promoção dos atrativos, por meio de mídias, além da produção e comercialização de souvenirs e cartões postais referentes aos locais. No fim do século XX e início do século XXI, a oferta destas atrações cresceu notavelmente, adaptando-as ao turismo e a edificações que, por algum motivo, real ou simbólico, estabelecem elos com a morte.

De fato, quando as pessoas viajam, elas foram atraídas - propositadamente ou não - para lugares, atrações ou eventos ligados, de uma forma ou de outra, com a morte, o sofrimento, a violência ou desastre. (STONE, P. The Darker Side of Travel. p. 4, 2009. Tradução da Autora).

Se a motivação para estas viagens está diretamente aliada aos signos e significados referentes à morte, trata-se, então, de uma questão delicada que merece maior atenção. No entanto, o deslocamento para estes locais existe, mesmo que não sejam o atrativo principal.

\section{EMOÇÕES E SENTIMENTOS}

A atividade turística está diretamente entrelaçada às emoções e sentimentos, considerando que muitas vezes a viagem torna-se sinônimo de realização, como, por exemplo, uma viagem de aniversário ou bodas. Dessa forma, o turista cria expectativas e quer se sentir realizado.

Os sentimentos são a nossa reação ao que percebemos e, por sua vez, eles colorem e definem nossa percepção do mundo. Na verdade, os sentimentos são o mundo em que vivemos (VISCOTT, p.11, 1982).

Entretanto cabe ressaltar que os impulsos gerados a partir da prática do Dark Turismo caracterizam diferentemente os sentimentos e as emoções; explica-se tal disparidade por meio das ações biológicas do organismo humano.

A distinção entre emoções e sentimentos pode ser evidenciada em casos clínicos em que pacientes perderam a capacidade de exprimir emoções e que assim também não conseguiam expressar os correspondentes sentimentos, porém alguns outros pacientes eram incapazes de possuir sentimentos, entretanto conseguiam expressar comportamentos emocionais, ou seja, é possível exibir uma expressão de medo, mas não sentir o medo. Assim, "os sentimentos são a expressão do florescimento ou do sofrimento humano, na mente e no corpo", "os sentimentos podem ser, e geralmente são, revelações do estado da vida dentro do organismo". A emoção e as várias reações com ela relacionadas estão alinhadas com o corpo, enquanto os sentimentos estão alinhados com a mente. (Disponível em: $<$ http://ateotalamo.wordpress. com/2011/03/28/existe-distincao-entre-sentimentos-e-emocoes/>. Acesso em: 10 mai. 2013).

De tal forma pode-se considerar a influência das emoções provocadas a partir da prática do Dark Turismo, pois elas desencadeiam as respostas posteriores ao contato com as atrações vinculadas. Quando se argumenta sobre qual foi a sensação predominante aos que visitaram os Campos de Concentração, por exemplo, grande parte enuncia o sentimento de tristeza, observando que:

Nos sentimentos, a reação é suave, conservando nosso ritmo e normalidade fisiológica. Mas, nas situações de emergência, surge a emoção que modifica esse ritmo e ativa a força muscular e hormonal. Esta vibração total é necessária para o desenvolvimento normal e funcionamento equilibrado do organismo e do psiquismo (IRALA, 1974, p.73).

\section{UTILIZAÇÃO DO TERRITÓRIO}

A apropriação do turismo sobre um determinado espaço o delimita como atração turística, considerando que durante a prática do turismo dá-se o consumo do espaço, devido à visita a tal território.

$\mathrm{O}$ turismo cria cenários com o intuito de destiná-los ao consumo do turista, aliando ao território aquilo que the desencadeia o desejo de "consumir", preceitos históricos e de identidade de um passado, que encantam e predispõem o turista a vivenciar 
situações por meio do local visitado, moldando o imaginário e estabelecendo visões simbólicas à memória do indivíduo. Contudo, demais fatores são responsáveis pelas alterações que influem no espaço em questão, entre os quais estão as mídias, devido ao poder de persuasão a elas concedido.

O turismo introduz novos códigos culturais e propõe novos sistemas de símbolos baseados em imagens que substituem a realidade e condizem a julgamentos segundo códigos impostos pela mídia. Assim a publicidade não se limita a designar um produto particular a vender, porém, pela utilização de uma linguagem e de meios de informação cuidadosamente elaborados, difunde-se uma imagem de um modo de vida e de uma ideologia inspirados por grupos líderes da população, aos quais convém imitar pelos seus comportamentos e hábitos de consumo. A insatisfação nascida do quadro de vida urbano é exacerbada, vendendo-se o espaço turístico como o paraíso. (RODRIGUES, 1997, p. 27).

Notando o interesse dos turistas em visitar territórios que caracterizam o Dark Turismo, observa-se a aplicabilidade do termo "turistificação", pois ela acontece de maneira a inserir no mercado aquilo que a globalização trouxe através da internet. Possibilitando a criação de novos atrativos, que não foram concebidos para tal destinação, surgem "novos destinos".

\begin{abstract}
A "turistificação" pode ser entendida como o processo de implantação, implementação e/ou de apoio da atividade turística em espaços turísticos ou com potencialidade para o turismo. A ferramenta para esse trabalho deve ser o planejamento estratégico integrado a atividade turística. (Disponível em: <http://turismonovilla2013.blogspot.com.br/2013/03/processo-de-turistificacao. $\mathrm{html}>$. Acesso em: 10 mai. 2013).
\end{abstract}

Pode-se analisar que os destinos de Dark Turismo, em grande parte, não foram criados para receber turistas, pois tiveram função vinculada com fatores marcantes da história da humanidade, como é o caso das antigas prisões.

\section{FAVELAS: A REALIDADE SOCIAL EM CONTRASTE COM O SOMBRIO}

O Brasil tornou-se precursor em destinar as favelas como oferta turística, atraindo visitantes desde 1992. Um dos maiores exemplos é a Favela da Rocinha, localizada entre os bairros de São Conrado e Gávea.

O roteiro já está consolidado e há oferta disponível aos inúmeros turistas que desejam observar a realidade social de uma comunidade. São passeios em carros abertos que possibilitam a visualização das moradias e que são comercializados por diversas agências de turismo receptivo.

Outro programa de turismo em favelas é o "Favela Tour", destinado, principalmente, aos estrangeiros. Trata-se de roteiro educativo que tem por finalidade apresentar a realidade da sociedade brasileira, além de propiciar à sua comunidade novas perspectivas.

Conforme pesquisa solicitada pelo Ministério do Turismo e aplicada pela Fundação Getúlio Vargas aos turistas que chegavam ao Aeroporto Tom Jobim, mais da metade do total de entrevistados deseja conhecer as favelas.

Assim como aborda Medeiros (2007), "turistas procuram experiências inusitadas, interativas, aventureiras e autênticas em destinos cujo apelo reside na antítese daquilo que se convencionou tratar como turístico". Identificando as favelas como um destes cenários opostos à realidade cotidiana do turista, são definidas as características comparadas ao Dark Turismo.

As características do turismo nas favelas são comparadas com as características do Turismo Sombrio, de forma geral, com a finalidade de comprovar o quanto são parecidos, em relação à forma como são formatados, promovidos e divulgados, bem como seu retorno para a população local. (PREZZI, 2009, p.10).

Isso significa que, neste aspecto, as favelas não necessariamente repassem a ideia de sofrimento e morte direta ou indiretamente. Contudo, o que se leva em consideração para ponderar o turismo em favelas como Dark Turismo é justificado pela forma que é configurado; por tratar-se de uma realidade que possibilita a reflexão, deve ser tratado com seriedade e há o desencadeamento de certa solidariedade.

O interesse histórico pelas lendas envolvidas atrai boa parte dos turistas aos locais. Alguns desses locais, dependendo do grau em que se encaixam no 
espectro de Stone (2006), são desenhados e formatados para servirem de entretenimento e diversão no meio dos sustos enquanto outros são configurados para transmitirem ideia de seriedade, cultura e educação. Alguns desses atrativos ainda tentam despertar a solidariedade e a preocupação social, como no caso do turismo em favelas. (PREZZI, 2009, p. 57).

As divergências entre opiniões a respeito da inserção da atividade turística em favelas como parte integralmente do Dark Turismo torna ampla a discussão, e os argumentos utilizados são diversos. É preciso ponderar as opiniões.

\section{FAVELAS E VIOLÊNCIA}

Pode-se considerar que, em algumas favelas, além do cenário típico de periferia, com casas amontoadas ou com lixo e esgoto a céu aberto, há também fatores diretamente ligados ao sofrimento e à morte, muitas vezes causados por chacinas. Um exemplo é o Roteiro da Chacina em Nova Iguaçu, baixada Fluminense, no Rio de Janeiro, onde no ano de 2005, vinte e nove pessoas foram mortas pela polícia militar sem motivos aparentes.

Posteriormente, em 2008 estabeleceu-se a proposta do projeto turístico "Roteiro da Chacina" no qual, além de compreender as representações históricas do território e conhecer a residência dos moradores, o turista também seria submetido aos questionamentos sobre região e a violência atribuída ao massacre.

Outras regiões no Rio de Janeiro também trazem traços das chacinas ligados aos cenários de periferia. É o caso da Chacina da Candelária ocorrida em 1993, hoje um dos espaços mais marcantes e que atrai a atenção de turistas internacionais. No episódio, em frente à igreja de mesmo nome, oito jovens que estavam dormindo nas escadarias foram alvejados e mortos por policiais militares. O Memorial traz as marcas dos corpos na calçada, da maneira que foram encontrados, além de uma cruz com os nomes das vítimas.

Compreende-se que este cenário também pode contribuir para a não violência, já que o acontecimento causou inúmeras sensações à comunidade, não somente na vizinhança, mas em regiões fora da cidade e no exterior. Além de ser uma maneira de denúncia, remete ao imaginário das pessoas que ali passam e visitam, retornando a cena trágica .
$\mathrm{Na}$ relação entre favelas e violência, muitas vezes marcada por mortes que não devem ficar impunes e ser esquecidas, ficam nítidas as atribuições que aliam o cenário em questão com o Dark Turismo.

Caso contrário, o turismo em favelas será pensado dentro do panorama histórico-cultural, evidenciando apenas as questões de urbanização, ou seja, haverá a banalização do assunto ao aplicar-se o termo Dark Turismo, e ocorrerá o uso da miséria alheia como uma mercadoria, esquecendo-se dos princípios éticos.

\section{CONSIDERAÇÕES FINAIS}

Diversas considerações norteiam o término deste trabalho. Foi possível perceber que o Dark Turismo engloba um campo de pesquisas ainda incipiente, capaz de possibilitar a continuidade de pesquisas em diversos campos.

A psicologia foi abordada no primeiro capítulo com o intuito de estabelecer a relação com a motivação do indivíduo, ou seja, o que o leva a visitar um local que está marcado por tragédias e sofrimento, que transmite emoções como tristeza e causa impacto ao dar-se a visita, quando os visitantes adquirirem conhecimento sobre a história do lugar visitado.

A atividade turística dá-se por meio da utilização do território, e, no caso do Dark Turismo, está inter-relacionado o processo de "turistificação", uma vez que os cenários visitados foram readaptados, com a intenção de receber turistas.

Todavia, estes mesmos cenários podem contribuir para uma relembrança de fatos trágicos, o que leva a uma reflexão sobre a violência urbana, e assim os atrativos tornam-se indiretamente um meio positivo para a paz. Inúmeros são os fatos ocorridos e utilizados pela atividade turística: o holocausto, o caso das torres gêmeas de 11 de setembro, a Chacina da Candelária, entre outros, que se tornaram espaços visitados para relembrar as tragédias ocorridas.

Dessa maneira, pode-se concluir que o turismo é uma ferramenta que auxilia no reconhecimento dos impactos gerados pela violência urbana, de modo a gerar reflexão em torno do assunto, levando o indivíduo a repensar determinadas atitudes que desencadeiam tal violência. Destaca-se, então, a importância do Dark Turismo, desde que bem planejado e com objetivos bem traçados para que não haja a banalização da vivência das pessoas. 
Sendo assim, o Dark Turismo planejado de forma adequada surge como agente benéfico ao tornar estas situações reconhecidas, favorecendo a luta por mudanças sociais, e não tornando-o objeto de sensacionalismo sobre situações violentas e trágicas.

Uma das dificuldades durante a produção do trabalho foi a escassez de bibliografia sobre o assunto, tornando nítida a possibilidade de se expandir o campo de estudo sobre os cenários de Dark Turismo.

Quando se busca informações de Dark Turismo no Brasil, surgem trabalhos que abordam as favelas como possíveis cenários; entretanto, essa conceituação merece maior campo de pesquisas, afinal a vivência cotidiana de uma sociedade não pode ser generalizada como um cenário relativo à violência urbana.

\section{REFERÊNCIAS}

ATÉ o tálamo. Existe distinção entre sentimentos e emoção? Disponível em: <http://ateotalamo.wordpress. com/2011/03/28/existe-distincao-entre-sentimentos-eemocoes/>. Acesso em: 10 de maio de 2013.

BARRETTO, M. Turismo e legado cultural: as possibilidades do planejamento. Campinas, São Paulo: PAPIRUS, 2000.

BARRETO, M. Manual de iniciação ao estudo do turismo. São Paulo: Papirus, 2001.

BENI, M. C. Análise estrutural do turismo. São Paulo: Editora Senac, 1998.

DIAS, R. Planejamento do turismo: política e desenvolvimento do turismo no Brasil. São Paulo: Atlas, 2003.

DENCKER, A. Métodos e técnicas de pesquisa em turismo. São Paulo: Futura, 1998.

DICTIONARIES Oxford. Disponível em <http:// oxforddictionaries.com>. Acesso em: 15 abr. 2013.

FORUM Dark Tourism. Disponível em: <http://www.darktourism.org.uk>. Acesso: 15 set. 2012.

FÓRUM Mundial Da Educação. Disponível em: <http:// www.adur-rj.org.br/5com/pop-up/FME_integracao_latina. htm>. Acesso em: 12 nov. 2013.

FURTADO, A. Turismo militar no concelho de Peniche. Escola Superior de Hotelaria e Turismo do Estoril, 2011.

HALL, S. A Identidade cultural na pós-modernidade. Tradução de Tomaz Tadeu da Silva. 7. ed. Rio de Janeiro: DP\&A, 2003.
IRALA, N. O controle cerebral e emocional. Edições Loyola, 1982

WEBER, D.; LEITE, R. Mais da metade dos turistas querem conhecer as favelas do Rio. O Globo. Disponível em: $\quad<$ http://oglobo.globo.com/rio/mais-da-metade-dosturistas-quer-conhecer-favelas-do-rio-7349831>. Acesso em: 10 set. 2013.

MEDEIROS B. A Favela que se vê e que se vende: reflexões e polêmicas em torno de um destino turístico. Revista brasileira de ciências sociais, v. 22, n. 65.

MENEZES, P. Roteiro da Chacina: que turismo é esse? Reflexões em torno de um projeto turístico polêmico. 2008.

MINISTÉRIO do Turismo. Disponível em: <http://www. turismo.gov.br>. Acesso em: 14 abr. 2013.

MINISTÉRIO do Turismo. Turismo no Brasil (2007-2010). Ministério do Turismo: Brasília, 2008.

MOESCH, Marutschka. A produção do saber turístico. São Paulo: Contexto, 2002.

PORTAL Administradores. Disponível em: < http://www. administradores.com.br/artigos/administracao-e-negocios/ teoria-de-maslow/28006/>. Acesso em: 16 jul. 2013.

PORTAL Info Escola. Disponível em: <http://www. infoescola.com/biografias/abraham-maslow/>. Acesso em: 29 jul. 2013.

PORTAL do Marketing. Disponível em: <http://www. portaldomarketing.com.br/Artigos/maslow.htm>. Acesso em: 15 abr. 2013.

PREZZI, A. Turismo Sombrio: uma viagem em busca do inusitado. Niterói: Universidade Federal Fluminense, 2009.

RODRIGUES, A. Turismo e Espaço: rumo a um conhecimento transdisciplinar. Hucitec, 1997.

ROSS, G. Psicologia do Turismo. São Paulo: Contexto, 2001.

STONE, P. The darker side of travel: the theory and practice of Dark Tourism. Edited by Richard Sharpley and Philip Stone, 2009.

TURISMO no Maestro 2013. Disponível em: <http:// turismonovilla2013.blogspot.com.br/2013/03/processo-de turistificacao.html>. Acesso em: 10 mai. 2013.

URRY, J. O olhar do turista: lazer e viagens nas sociedades contemporâneas. 3. Ed. Livros Studio Nobel Ltda, 1996.

VISCOTT, D. A linguagem dos sentimentos. São Paulo: Summus, 1982.

Recebido em dezembro de 2013. Aceito em março de 2014. 